\title{
Dental treatment on a German warship during a three-month deployment
}

\author{
Cornelius von Wilmowsky, ${ }^{1,2}$ M R Kiesewetter, ${ }^{3}$ T Moest $^{1}$
}

${ }^{1}$ Army Medical Center, Bad Reichenhall, Germany

${ }^{2}$ Department for Oral and Maxillofacial Surgery, University Hospital Erlangen, Erlangen, Germany

${ }^{3}$ German Naval Academy, Flensburg, Germany

\section{Correspondence to}

Capt Cornelius von Wilmowsky, Department of Oral and Maxillofacial Surgery,

Friedrich-Alexander-University Erlangen-Nuremberg,

Glueckstrasse 11, Erlangen D-91054, Germany; cornelius.vonwilmowsky@ukerlangen.de

Received 8 March 2013 Revised 12 June 2013 Accepted 16 June 2013 Published Online First 18 July 2013
To cite: von Wilmowsky $C_{\text {, }}$ Kiesewetter MR, Moest T. I R Army Med Corps 2014; 160:42-45.

\section{ABSTRACT}

Introduction Despite routine dental screenings and treatments before military deployments, dental emergencies may arise due to acute infections, trauma or failed restorations. The purpose of this study is to evaluate the dental service during a three-month deployment on a German warship.

Methods A retrospective analysis of dental attendances and treatments in a German naval task group of three ships with an average total of 650 soldiers. Diagnosis, treatments performed, percentage of emergencies, routine procedures and numbers of appointments were recorded.

Results Out of 650 soldiers, there were 71 patients $(10.92 \%)$ with a mean age of $25.1 \pm 5.3$ years. Out of 136 treatments, $17.65 \%$ were for emergency treatment, which is equivalent to $3.69 \%$ of all servicemen of the task group. Combining the reasons for dental emergencies, $95.84 \%$ were caused by caries.

Conclusions The pre-screening of sailors before an overseas deployment is necessary to avoid severe dental treatments. Caries remains the main cause for dental emergencies, and medical doctors should be trained to treat caries lesions if a dentist is not on board.

\section{INTRODUCTION}

The growing number of military deployments abroad has increased the requirements for the military system in general and for the German Navy as an expeditionary navy in particular. Operational readiness is a prerequisite to meet the physical demands of military missions; this readiness also includes oral health.

A fundamental purpose of military dental services is to ensure that the operational effectiveness of soldiers is not compromised during deployments due to oral ill health or disability. Thus, the German Army and other national armies have introduced a dental classification system to ensure the oral health of servicemen and to identify personnel who are not deployable due to dental conditions. $^{12}$

The aim of this classification system is to create standards of dental fitness for the military personnel of NATO countries in order to reduce to the lowest level possible, the number of dental emergencies during an operation or mission. ${ }^{2}$ To reduce the possibility of dental emergencies during a deployment, priority should be given to complete oral rehabilitation in the home country. Therefore, German soldiers have to fulfil Dental Fitness Class (DFC) 2 (no dental emergency expected within the next 12 months) or higher before deployment. Even with predeployment dental requirements,

\section{Key messages}

Caries remains the main cause for dental emergencies on board military ships.

- If a dentist is not on board, medical doctors should be trained in the excavation of caries, trepanation, medical root canal treatment, temporary fillings and recementing of failed restorations, in order to handle dental emergencies.

- Soldiers with a lower rank have a higher probability of being treated for a dental emergency during overseas deployments.

dental problems and emergencies can occur among deployed military personnel.

A special problem arises with seagoing units. Being deployed away from home, personnel on board naval vessels have restricted access to professional dental care during their mission deployment.

Situations may arise in which acute infections, untreated dental problems, or failed restorations may result in pain, impairing human performance as well as negatively affecting the operational readiness.

Even though the number of military deployments is rising, data regarding dental emergencies and treatment on board military vessels is rare. Few papers have been published that report the occurrence of dental emergencies and evaluate the nature of dental attendances aboard warships. ${ }^{3-5}$

It would be useful to obtain data to examine the specific kind of dental emergencies and treatments that can be expected, making it possible to optimise the medical supply for the crew with regard to equipment and training of the dentist during the mission.

Therefore, this retrospective analysis of dental attendances and treatments in a German naval task group during a three-month deployment (JanuaryMarch 2010) could give a general overview in order to evaluate the standards of premission preparation. Moreover, the collected data could outline the requirements of professional dental treatment of naval forces during deployments.

\section{METHODS}

The German naval task group consisted of three ships: one combat support ship (CSS, 200 servicemen) and two frigates (frigate 1 (240 servicemen) and frigate 2 (210 servicemen), carrying 650 servicemen in total. There was one medical doctor on 
Figure 1 Dental unit of the mobile Navy emergency center located on the combat support ship (A). (B) Shows the micromotor with handpiece (NSK Surgic XT Plus, NSK Europe GmbH, Germany) for surgical interventions.
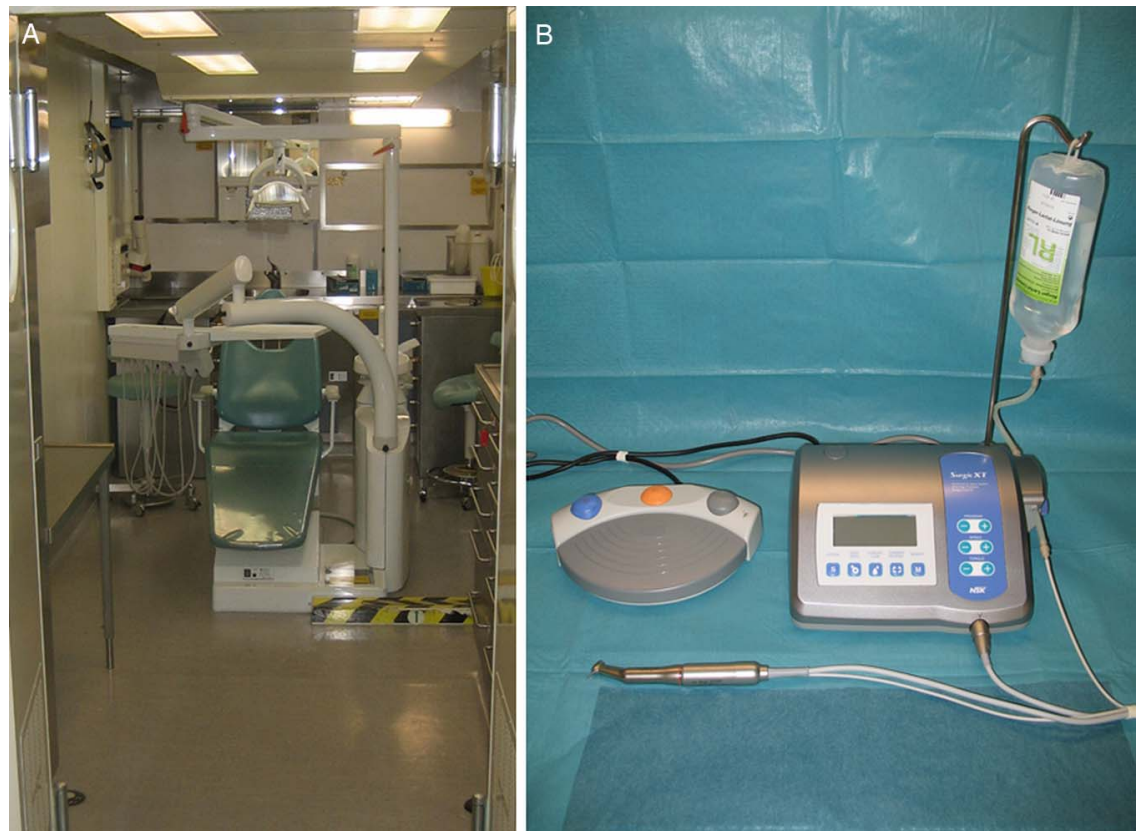

each of the three ships of resident (speciality registrar) grade. On the CSS, the medical team consisted of a medical doctor, a dentist, a surgeon and an anaesthesiologist with a specialisation in intensive care.

The CSS carried a navy emergency rescue centre (Marineeinsatzrettungszentrum (MERZ)) consisting of 26 containers. It included two operation rooms, four intensive care beds, a dental care unit (Figure 1A), support units, such as sterilisation, $\mathrm{x}$-ray and microbiology facilities, as well as a dental technician laboratory.

The dental unit was equipped with a single chair (Kavo 1066, Kavo Dental GmbH, Germany) and a chair-side x-ray apparatus for single-tooth radiography. Furthermore, panoramic radiography was available. For surgical interventions such as osteotomies, a surgical micromotor with a handpiece was available (NSK Surgic XT Plus, NSK Europe GmbH, Germany) (Figure 1B).

Regular daily office hours were offered in the morning and the afternoon 6 days a week as part of the sea and harbour routine. Dental emergencies were treated at all times. The dentist had surgical experience due to a civilian employment at a hospital department for oral and maxillofacial surgery. All tasks related to dental treatment, such as instrument preparation, sterilisation and documentation were performed by a dental assistant who also assisted in scheduling appointments.

For all patients, their gender, age, unit and reason for consultation were recorded in a written log book by the dental assistant and checked by the dentist. After deployment, the log book was anonymised, and the collected data was retrospectively analysed independently.

Procedures performed included dental records, fillings, endodontics (root canal treatment), extractions, repair or recementing of failed restorations, as well as dental cleaning.

If medically necessary, removable occlusal splints fitting the lower arches of teeth were manufactured in the technician laboratory (Figure 2).

The data and analysis might be affected by routine changes of personnel over the studied time period which may introduce minor variance in results but not of sufficient magnitude to affect the overall analyses and its implications.
To analyse the incidence rates per 100000 person-days at sea, the number of initial visits for a dental problem was the numerator and the total number of person-days underway was the denominator. $^{4}$

\section{RESULTS}

Diagnoses treated are detailed in Table 1.

Dental treatment on board the CSS was received by $71 / 650$ $(10.9 \%)$ of the task group with a mean age of $25.1 \pm 5.3$ years, the total number of attendances during the three-month deployment was 136, and there were 202 treatments in total (Table 2).

There were 24 dental emergencies $3.69 \%$ of all task group servicemen, $33.8 \%$ of all patients and $17.7 \%$ of all attendances),

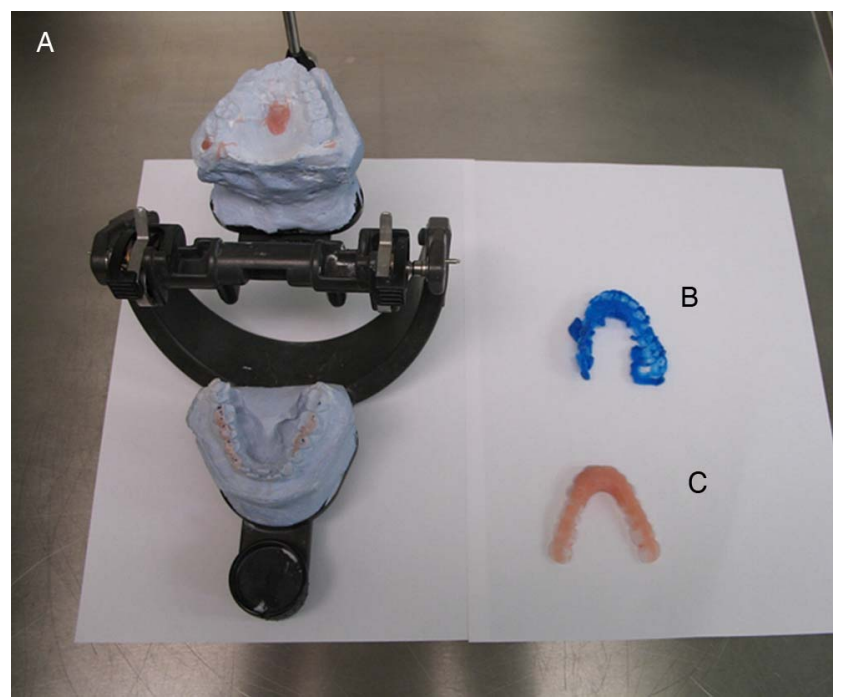

Figure 2 Plaster cast $(A)$ with the mush bite $(B)$ and the removable occlusal splint which fits the lower arches of teeth. The splint resembles a Michigan-type occlusal splint with the aim of relaxing the jaw muscles (C). All technical dental work was done in the dental technician laboratory by the dentist. 


\begin{tabular}{|c|c|c|c|}
\hline Diagnosis & n (\%) & Diagnosis & n (\%) \\
\hline Caries & $62(59.62)$ & $\begin{array}{l}\text { Defective/missing } \\
\text { restoration }\end{array}$ & $4(3.85)$ \\
\hline Dentinal hypersensivity & $13(12.5)$ & $\begin{array}{l}\text { Other endodontic } \\
\text { problems }\end{array}$ & $2(1.92)$ \\
\hline Pulpitis & $12(11.54)$ & Periradicular abscess & $1(0.96)$ \\
\hline $\begin{array}{l}\text { Temporomandibular joint } \\
\text { pain }\end{array}$ & $9(8.65)$ & Pericoronitis & $1(0.96)$ \\
\hline
\end{tabular}

equating to 147.7 dental emergencies per 1000 soldiers per year.

Only one soldier was not DFC 1 (not requiring dental treatment) $(23.82 \%)$ or DFC 2 (unlikely to need emergency dental treatment within 12 months) (76.03\%); he was DFC 3 (likely to have a dental emergency in the next 12 months) and had slipped through the obligatory dental screening prior to deployment. Overall, $99.85 \%$ of the soldiers were dentally fit (DFC 1 or 2).

\section{Emergency treatments}

Emergency treatment included definitive or temporary endodontic treatment, excavation of caries and fillings, surgical tooth extraction and surgical treatment of pericoronitis. All endodontic treatments were caused by deep caries affecting the pulp, and all fillings were also related to caries. Combining the reasons for the dental emergencies, $95.84 \%$ of the emergencies were caused by caries (endodontics 50\%, fillings $41.67 \%$, surgical tooth extraction due to a periradicular abscess $4.17 \%$ ). One patient attended with pericoronitis caused by a partially erupted mandibular third molar requiring excision of the operculum and drainage of the pus plus a course of an oral antibiotic. No case of dental trauma occurred.

The majority of patients treated were stationed on board the CSS (43 patients). Consultations from patients stationed on board the frigates were largely due to dental emergencies (17 emergency treatments out of $24(70.83 \%)$. These patients were treated during stays in ports. In severe cases during sea phases of the mission, it was possible to transfer a patient from a frigate to the dental unit onboard the CSS, but this was not done during the deployment. The number of patients and emergency treatments for each ship and in total is shown in Table 3.

Most of the patients who attended due to a dental emergency were enlisted soldiers (6.16\% of all enlisted soldiers) compared with $3.06 \%$ of the non-commissioned officers, and $1.72 \%$ of the officers.

Table 2 Treatments performed and percentage of total treatments

\begin{tabular}{lllr}
\hline Treatment & $\mathbf{n}(\%)$ & Treatment & $\mathbf{n}(\%)$ \\
\hline Restoration & $62(30.69)$ & Occlusal splint & $9(4.46)$ \\
Dental examination & $58(28.71)$ & Recementing of restoration & $4(1.98)$ \\
Dental cleaning & $38(18.81)$ & Surgical tooth extraction & $1(0.5)$ \\
Endodontics & $14(6.93)$ & Incision (pericoronitis) & $1(0.5)$ \\
Desensitisation & $13(6.44)$ & Antibiotics prescription & $2(1)$ \\
& & Total & $202(100)$ \\
\hline
\end{tabular}

Table 3 Distribution of patients and emergency treatments for each ship and for the task group

\begin{tabular}{lccc}
\hline & $\begin{array}{l}\text { Combat } \\
\text { support ship }\end{array}$ & Frigate 1 & Frigate 2 \\
\hline Number of servicemen & 200 & 240 & 210 \\
$\begin{array}{l}\text { Number of patients } \\
\text { Number of dental emergencies }\end{array}$ & 73 & 8 & 20 \\
$\begin{array}{l}\text { Percentage of patients out of ship } \\
\text { crew (\%) }\end{array}$ & 21.5 & 6 & 11 \\
$\begin{array}{l}\text { Percentage of patients out of task } \\
\text { group (\%) }\end{array}$ & 6.61 & 3.3 & 9.5 \\
$\begin{array}{l}\text { Percentage of emergency } \\
\text { treatments out of ship crew (\%) }\end{array}$ & 3.5 & 1.23 & 3.08 \\
$\begin{array}{l}\text { Percentage of emergency } \\
\text { treatments out of task group (\%) }\end{array}$ & 1.08 & 2.5 & 5.23 \\
\hline
\end{tabular}

\section{Routine treatments}

Routine treatments included dental records, fillings, endodontic treatment, desensitisation of tooth necks as well as dental cleaning. In five cases of temporomandibular dysfunction, the indication for an occlusal splint was identified and the splints were manufactured by the dentist in the technician laboratory (Figure 2) and were able to be successfully applied. Treatment of temporomandibular dysfunction included the prescription of non-steroidal anti-inflammatory drugs to reduce inflammation and as an analgesic to reduce pain in the acute phase. The splint resembled a Michigan-type occlusal splint with the aim of relaxing the jaw muscles.

Other treatments included the removal of a tooth retainer, which was without function. In one case, the medical doctor asked for help in decompressing a subungual haematoma which was achieved using a handpiece and a diamond-coated drill to perforate the fingernail and decompress the haematoma. Five patients consulted the surgeon with acute paronychia caused by ingrowing toenails and were treated using dental drills to avoid more invasive surgery. ${ }^{6}$

\section{DISCUSSION}

Routine access to the dentist at the naval military base in the home country is difficult, considering the frequent absence from home caused by mission and combat training phases, as well as the deployment in combined and/or joint mission environments itself. Often units are deployed for 6 months of the year.

Aside from predicting resource needs, we also need systematic reporting of dental emergencies in order to monitor the adequacy of dental support during an ongoing major deployment. There is little literature reporting the occurrence of dental emergencies and evaluates the nature of dental attendances aboard warships. ${ }^{3-5}$ There are some reports of dental practice on cruise ships, ${ }^{7-9}$ but it is difficult to apply this data to military ships since the distribution of the sexes and ages of passengers as well as duration of cruises does not match those of military naval vessels. Statistics about cruise ships indicate that the mean age of passengers is 49 years and the mean duration of a cruise is 7 days. $^{7}$ On long cruises of more than 3 months' duration, a mean passenger age of 70 years has been reported in comparison with the mean age of the patients in our study (25.1 \pm 5.3 years). ${ }^{10}$

Our study demonstrated 147.7 dental emergencies per 1000 soldiers per year, which is in keeping with dental emergency rates at two expeditionary medical support facilities supporting 
operations 'Enduring' and 'Iraqi Freedom'. In a retrospective cohort analysis of about 11000 soldiers, Dunn and colleagues found a rate of 145-153 dental emergencies per 1000 soldiers per year, ${ }^{11}$ most of the emergencies were due to dental caries. This is also in accordance with an analysis of dental morbidity in the UK armed forces in Iraq. ${ }^{12}$ Even though these studies deal with ground forces, the results are similar to studies about servicemen aboard navy vessels. ${ }^{3}$ British Royal Navy planners expect 5.2\% unscheduled dental attendances on warships.

The incident rate in our study for dental emergencies was 41 per 100000 person-days. A study by Deutsch found an incident rate of 5.0 per 100000 person-days evaluating 240 submarine patrols, ${ }^{4}$ and it is suggested that the dental screening of US submariners is more intense, and thus more effective, compared with other branches of the military system and other western countries. $^{4} 13$

The rate of dental emergencies demonstrates the need for trained dental personnel on ships. It is not always possible to deploy a dentist, and thus the German Navy doctors take part in a one-week course where they learn to handle dental emergencies at sea. Training topics include excavation of caries, trepanation, medical root canal treatment, temporary fillings and recementing of failed restorations. ${ }^{14}$

If a dentist is available nearby, servicemen are more likely to seek a consultation. Most of the visits were made by servicemen of the CSS, which makes sense due to the ease of access not being a barrier to dental treatment. The high rate of attendance is therefore not unexpected.

An interesting observation is that no traumatic injury of a tooth had to be treated. It has been reported that $11 \%$ of unscheduled attendances on British warships are due to trauma, ${ }^{3}$ although Alexander and colleagues do not report the causes of the dental trauma. It has been reported that impact from a weapon can be a major risk factor for traumatic dental injuries in soldiers ${ }^{15}$ in a study performed on soldiers during basic training. On ships, only guards carry weapons and there is no running or jumping with weapons held out in front of the body, thus eliminating a major risk factor for traumatic tooth injuries. Nevertheless, the reasons for the differences between our findings and those of Alexander remain unclear.

The German military dentally screens its soldiers prior to deployments, and they must be DFC 1 or 2 to deploy to reduce the number of dental emergencies to the lowest level possible. The benefits of this are demonstrated by the one soldier who was missed by predeployment screening, who deployed when DFC 3. He presented with severe pain due to a deep carious lesion in an upper molar which required removal by osteotomy, making surgery necessary. This particular case reinforces two facets: it is of great advantage if the dentist on board a ship is surgically experienced, and secondly that screening and targeting dental treatment of servicemen prior to deployment effectively reduces dental emergencies at sea. ${ }^{4}$

Considering that dental caries is also the main cause of pulpal disease and the main reason for fillings or failed restorations, it is the most important disease the dentist has to deal with, as over $95 \%$ of our dental emergencies were due to caries which has been previously reported on board military vessels ${ }^{3}$ and in deployed military personal. ${ }^{16}$

Soldiers with a lower rank have a higher probability of being treated for a dental emergency during overseas deployments. Thus, there exists a difference in dental health between officers, non-commissioned officers and enlisted soldiers in the German Navy. Enlisted soldiers showed a 3.5-fold higher probability of a dental emergency compared with the officers, and this probability was twice as high in comparison with the non-commissioned officers. This might be a reflection of the sociodemographic backgrounds from which they are drawn, concluding that dental health has to be improved for the lower ranks. ${ }^{17} 18$

The excellent dental equipment on board the CSS (including MERZ) and the availability of a dental nurse made it possible to offer regular dental treatment; while not formally measured, it was noted that the crew were thankful for the possibility of receiving regular treatment, as servicemen had the opportunity to check or improve their dental status without conflicting with duty attendance.

\section{CONCLUSION}

The dental emergency rate during a three-month naval deployment was 147.7 per 1000 soldiers per year. The data shows that caries remains the main threat for the occurrence of dental emergencies, so it is necessary for medical doctors to be trained to treat caries and endodontic emergencies if a dentist is not on board. There is a relation between rank and the occurrence of a dental emergency.

Contributors CrW: The dentist onboard the warship. He treated the patients and collected the data. MRK: Officer onboard the warship. He also collected data and helped writing the manuscript. TM: Surgeon who helped analysing the data and helped writing the manuscript.

\section{Competing interests None.}

Provenance and peer review Not commissioned; externally peer reviewed.

Data sharing statement Available upon request.

\section{REFERENCES}

1 Richardson PS. Dental risk assessment for military personnel. Mil Med 2005; 170:542-5.

2 North Atlantic Treaty Organization Standardization Agreement (STANAG) 2466 Dental Fitness Standards and Classification System for Military Personnel ED 2. 2007.

3 Alexander DC. Dental recall status and unscheduled dental attendances in British warships. Mil Med 1996;161:268-72.

4 Deutsch WM. Dental events during periods of isolation in the U.S. submarine force. Mil Med 2008;173:29-37.

5 Mausberg R, Hornecker E, Rellermeier I. Fallstudie zur Mundgesundheit auf einem Schiff der Bundesmarine. Wehrmedizinische Monatsschrift 2000:65-70.

6 von Wilmowsky C, Haber A, Kalmbach A, et al. Alternative treatment of paronychia on board of a naval vessel. Wehrmedizinische Monatsschrift 2011;55:31-3.

7 Sobotta BA, John MT, Nitschke I. Dental practice during a world cruise: characterisation of oral health at sea. Int Marit Health 2006;57:136-48.

8 Sobotta BA, John MT, Nitschke I. Cruise medicine: the dental perspective on health care for passengers during a world cruise. J Travel Med 2008;15:19-24.

9 Sobotta BA, John MT, Nitschke I. Dental practice during a world cruise: treatment needs and demands of crew. Int Marit Health 2007;58:59-69.

10 Sobotta BA, Reiber T, Nitschke I. Oral health of seafarers-a review. Int Marit Health 2011;62:8-16.

11 Dunn WJ, Langsten RE, Flores $\mathrm{S}$, et al. Dental emergency rates at two expeditionary medical support facilities supporting operations enduring and Iraqi Freedom. Mil Med 2004;169:510-14.

12 Richardson PS. Dental morbidity in United Kingdom Armed Forces, Iraq 2003. Mil Med 2005;170:536-41.

13 Payne TF, Posey WR. Analysis of dental casualties in prolonged field training exercises. Mil Med 1981;146:269-71.

14 Eikenberg S, Keeler R, Green T. Use of the Army Dental Command Corporate Dental Application as an electronic dental record in the Iraq theater of operations. US Army Med Dep J 2011;51-7

15 Becker T, Ashkenazi M. Incidence of reported dental trauma among soldiers during basic training. Mil Med 2009;174:190-2

16 Chisick MC, King JE. Dental epidemiology of military operations. Mil Med 1993;158:581-5

17 Elmer TB, Langford J, McCormick R, et al. Is there a differential in the dental health of new recruits to the British Armed Forces? A pilot study. Br Dent J 2011;211:E18.

18 Badel T, Restek-Despotusić S, Kern J, et al. Caries in Croatian Army recruits in 2000. Acta Med Croatica 2006;60:315-18. 